The following items, though not yielding calories, were included to increase interest in the fare: curry powder, Marmite, salt and pepper. Finally, tea and coffee were introduced as drinks, both in a soluble form which considerably simplifies preparation.

This sledging ration is based on two previous Medical Research Council prototypes which have been used in the field. We have asked the users of our boxes to complete a full questionnaire and from their answers we will be guided as to further modifications. It is hoped that the M.R.C. rations may become available commercially and that only small changes from time to time will be necessary to keep them up-to-date. This will simplify the victualling problems of expeditions, for the final product will represent the accumulated experience of a large number of polar travellers.

\title{
REFERENCES
}

Cherry-Garrard, A. (1948). The Worst Fourney in the World. London: Penguin Books. Johnson, R. E. \& Kark, R. M. (1947). Science, ro5, 378.

Masterton, J. P., Lewis, H. E. \& Widdowson, E. M. (1955). Proc. Nutr. Soc. 14, xvi.

Masterton, J. P., Lewis, H. E. \& Widdowson, E. M. (1957). Brit. F. Nutr. xI, 346.

\section{Heat stress and nutrition}

By R. H. Fox, National Institute for Medical Research, Holly Hill, London, N.W.3

The manner and extent of the modifications to man's nutritional needs and status resulting from exposure to the heat stress of tropical living have long been of interest to physiologists.

Early writers were perhaps mainly concerned with the immediate effects of individual items of food. Paulus Aegineta ( 1844 ) commenting on the properties of pot-herbs in the seventh century writes: "The lettuce is manifestly refrigerant and moistening; it is therefore soporific, and, compared with other pot-herbs, nutritious, forming blood of a very good quality.' Others, a little more recently, have made some very shrewd comments. Thus Parkes (I 883), when discussing the diet of troops in India some time before $188_{3}$, gives this advice: 'Our best guide at present for the quantity of food to be taken in the tropics, is to apportion it to the amount of mechanical work done, as in temperate climates. In India, as elsewhere, it must be in balance with exercise.' The reviewer of today has the benefit of an enormous mass of relevant data and yet he wonders whether we can really improve much on this advice.

Our knowledge of the associations between heat stress and nutrition comes partly from observations made in field studies, partly from the results of laboratory experiments and also, more recently, from valuable combinations of both these approaches.

\section{Assessment of evidence from nutritional field studies}

Nutritional field studies are exceedingly useful in establishing the important associations between dietary deficiencies and clinical signs of malnutrition, in 
revealing the existence of problems, and in providing human cases for detailed study. Unfortunately, they have limitations which become particularly obvious when attempts are made to use the results of such studies to define the role of so wide-spread or diffuse a factor as heat stress in modifying man's nutritional status. These limitations are generally appreciated, but the reasons for them are so important that they are worth repeating briefly. The main difficulty is clearly the enormous number of variables with their complex interactions involved in any field situation, so that the contribution from any one factor becomes exceedingly hard to disentangle from all the others. Thus, we have associations between nutritional diseases and infectious diseases, and of both with the climate. The climate is a factor in determining the crops grown and the quality of the diet eaten, and even the effects of differences in social customs and racial characteristics must be considered. Furthermore, whereas there is a single criterion to determine the presence or absence of infectious disease there is often no sharp border-line between health and malnutrition. We are still handicapped by the difficulty of detecting clinically the presence of a condition as important as protein deficiency.

It is perhaps no wonder, therefore, that even in the pathogenesis of pellagra, in which some association between climate and dietary factors has long been recognized, our knowledge of the true relationship is still very uncertain. Thus Gillman \& Gillman ( $195 \mathrm{I}, \mathrm{p}, 37$ ), after discussing the correlation of pellagra with climatic factors, say: 'Nevertheless, one major feature emerging from the above analysis is that in some way the solar radiations and the seasonal variations thereof, profoundly affect the manner in which malnutrition will become manifest and in some way determine the World distribution as well as the annual variations in the incidence of pellagra.' After considering the effect of diet they comment (p. $\left.5^{6}\right)$, 'Neither a specific kind of diet nor a specific variety of climate alone is adequate to convert chronic malnutrition into pellagra. Apparently the two, inter-acting through the organism, are required. When viewed in this perspective, the relation between the world distribution and the seasonal incidence of pellagra, together with the types of diets consumed by malnourished people, may not be entirely accidental.'

For the present, therefore, rather than trying to answer the question 'What can we learn of the effect of climatic stress by comparing the results of nutritional studies made on man living in hot climates with those from cooler climates?', it may prove more fruitful to pose the question 'How does man respond to heat stress and how might such a response affect his nutritional status?'

\section{Physiological responses on acclimatization to heat}

The essential features of man's immediate response on passing from a cool to a warmer climate are now fairly well established. Physiological adjustments have to take place to maintain the thermal equilibrium of the body. To achieve the same rate of metabolic heat loss from the surface of the body by the avenues of convection, conduction and radiation, the skin temperature must rise to maintain the same thermal gradient between the skin and air. The higher skin temperature reduces 
the temperature gradient between the skin and the deeper body tissues and so, in order to maintain the same rate of heat flow outwards, there is an increase in blood flow in the skin. In hot climates, or if there is a sufficiently high metabolic heat production, this mechanism of temperature regulation by peripheral circulatory adjustments is inadequate; the excess heat is then lost by utilizing the latent heat of evaporation of sweat. In excessively hot or humid conditions, or as the result of exercise in the tropics, even the sweating mechanism may be unable to dissipate sufficient heat and then the deep-body temperature rises. Such a rise in body temperature can, for short periods, help to re-establish thermal equilibrium by increasing the temperature gradient between the skin and the environment.

In addition to the immediate responses on exposure to a hot environment, there are certain further physiological adjustments which take place after frequently repeated or continual exposure to the hot condition and which result in a great improvement in the ability to withstand its stress and in the ability to work in it with less subjective discomfort. These longer-term adaptive phenomena, called acclimatization processes, include among others: a more rapid thermo-regulatory response to a change in the level of stress, an increase in the blood volume, an increase in the volume of sweat produced, a decrease in the salt content of the sweat, and a smaller rise in deep-body temperature and pulse rate during work. There is no evidence that the African shows any racial difference in his ability to acclimatize to severe heat as compared with the European (Ladell, I95 I).

\section{Effects of heat acclimatization on nutritional status}

Some of the possible effects of these thermo-regulatory changes on the nutritional status can be considered as follows:

(I) The effect of high environmental temperatures on human energy requirements.

(2) The loss of body nutrients through sweat and dermal losses.

(3) Heat stress and the general adaptation syndrome.

(4) The combined effects of heat stress and malnutrition on skin function.

Energy requirements in hot climates. 'The deep-body temperature of a man at rest in the tropics is only a little above that found in cooler climates (Adam \& Ferres, I954), but this increase, together with a higher skin temperature, might be expected to result in a higher basal metabolic rate. The oxygen consumption of skin tissue is, however, probably small (Fuhrman, I956), so that its contribution to the total B.M.R. would not be large. An analysis of the results of studies on the B.M.R. reported from many countries, with climates ranging from arctic to tropical, revealed a negative correlation between the B.M.R. and the prevailing air temperature (Quenouille, Boyne, Fisher \& Leitch, I95 I). In the analysis it was not possible to isolate the effects of all the variables mentioned earlier and the possibility remains that this apparent effect with temperature is really the result of some other factor, such as nutritional status. A disinclination for physical exertion, thus avoiding the stress of extra heat elimination, is probably a normal adaptation to tropical living; this, together with the lighter clothing worn in the tropics (Gray, Consolazio \& 
Kark, I95I), may partly explain the lower voluntary calorie intakes observed in hot climates compared with cool climates in comparable groups of fit, young soldiers (Johnson \& Kark, I947). Recent studies provide little evidence that the energy expended performing a standardized work routine is altered in moderately hot climates (Ferres, Fox \& Lind, 1954). As a guide to those who have to compute calorie requirements it has been tentatively recommended that 'for every $10^{\circ} \mathrm{C}$. departure in mean annual temperature from the reference temperature of $10^{\circ} \mathrm{C}$, , requirements should be adjusted by $5 \%$ of the requirements at the reference level, the $5 \%$ being subtracted for higher temperatures and added for lower temperature' (Food and Agriculture Organization of the United Nations: Committee on Calorie Requirements, 1957).

Losses of nutrients from the body surface. The sweat glands of normal individuals are able to conserve most body nutrients very efficiently. Thus the losses of all the vitamins are small (Mitchell \& Edman, I95I) and only traces of glucose appear (Lobitz \& Osterberg, 1947). The losses of nitrogenous compounds, other than urea, are also almost certainly small, but have proved difficult to measure because of the contamination of sweat with products of dermal origin (Rothman, 1954). Surprisingly high concentrations of lactic acid are found in sweat (Weiner \& van Heyningen, 1949; Thurman \& Ottenstein, 1952), but after acclimatization the concentration is apparently reduced (van Heyningen \& Weiner, 195 I; Dill, Hall \& Edwards, 1938). The important mineral constituents of sweat are the chlorides of sodium and potassium, and iron. The sweat of unacclimatized individuals may contain more than $4.0 \mathrm{~g}$ salt/1., but on exposure to heat stress and a low salt intake the content may fall to as little as $0 . \mathrm{I} / \mathrm{g}$. (Conn, I949). This salt-conservation mechanism is thought to be activated by the production of pituitary adrenocorticotrophic hormone stimulating the adrenals to secrete the 'salt active' adrenal cortical steroids. In contrast with sodium, the sweat glands are apparently unable to conserve potassium, and the concentration in sweat approximates to that of tissue fluid (Dill et al. 1938). There is also a dermal loss of potassium, so that individuals resting in a cool environment may lose more potassium chloride than sodium chloride from their skin (Hancock, Whitehouse \& Haldane, I 929). These potassium losses through the skin are of particular interest in view of the reports of hypokalaemia in severe cases of kwashiorkor with diarrhoea (Hansen, 1956; Politzer \& Wayburne, I957).

It is difficult at present to form any reliable estimate of the amounts of protein lost from the body surface through shedding of keratinized epithelium (Rothman, 1954), but if four applications of Scotch tape to the skin surface can increase its mitotic index more than four times (Pinkus, 1952) it seems almost certain that a greatly increased rate of protein loss must occur as the result of the maceration of skin with sweating in tropical conditions. A loss of iron from the skin of $6.5 \mathrm{mg}$ daily in non-sweating individuals has been reported (Mitchell \& Hamilton, 1949) and the rate of loss was increased by sweating. Here also the losses may be of some importance in view of the wide-spread distribution of iron-deficiency anaemias in tropical communities. Fat losses from the skin surface are probably quite large, but vary a great deal from one individual to another, and in the same individual 
from time to time (Rothman, I954, Chap. 12). Losses of calcium may also be significant (Mitchell \& Edman, 1951). None of these normal sweat and dermal losses of nutrients would seem likely to be of much consequence except when the dietary intake is already on the border-line of inadequacy.

Heat stress and the general adaptation syndrome. It has been suggested that if an organism is continuously exposed to any form of stress there is a common pattern of reaction passing through the stages of alarm, resistance and, finally, to exhaustion. The reactions described include loss of body-weight and nitrogen, a rise in plasma potassium and a fall in chlorides, and an increase in the corticotrophic hormone with a suppression of gonadotrophic, lactogenic and growth hormones (Selye, 1946). It is difficult to escape the conclusion that if this concept is correct, which is certainly disputed (Gillman \& Gillman, r95I), it must play a very important role in tropical communities, where the stresses of a high incidence of infectious diseases, malnutrition, insecurity and a hot climate are all combined.

The combined effects of heat stress and malnutrition on skin function. The main impact of the heat stress of life in the tropics falls first on the skin, for it has the function of protecting the deeper tissues not only from fluctuations in temperature but also from the deleterious effects of solar radiation. Evidence of this stress can be seen in the high incidence of skin diseases in tropical communities (Macpherson, 1956). It has been known for a long time that the appearance of skin changes in times of famine or undernutrition (McCance \& Barrett, 195I), and changes in skin texture such as 'dry' skin, 'mosaic' skin and 'crackled' skin are commonly found in tropical communities living on inadequate diets. Skin which appears abnormal clinically may show no recognizable histological defect or only minimal signs of imperfect keratinization (McCance \& Barrett, 195I). At the other end of the scale there are the severe dermatoses seen in pellagra and the rather similar lesions sometimes seen in kwashiorkor. Our knowledge of what these changes mean in terms of disturbed functioning of the skin as an organ and in its role in the metabolism of the body as a whole is, however, exceedingly meagre. This is a field where we should probably look for further advances to come from the cytochemist rather than the histologist. Furthermore, if one wishes to follow changes in the activity of an enzyme system it is surely much easier to obtain punch-biopsy specimens of the skin than, for example, from the liver. For the present we have to be content with a few tantalizing clues. One of these concerns the sulphur-containing aminoacids, especially cystine, which probably play an important role in the formation of epidermal keratin (Rothman, I954, Chap. I6). Cystine is not an essential aminoacid, and can be formed from methionine in vivo in the skin (Dawbarn, 1938). The sulphur content of skin is as high as $0.4-0.5 \%$ in infants and then falls with age; it is thought that the skin may act as a depot for sulphydryl compounds on which demands are made when these compounds are needed during infections and intoxications (Klauder \& Brown, I936). In view of the known importance of the sulphur-containing amino-acids in dietary liver disease in rats (Himsworth, I950), it has also been suggested that they may represent a metabolic link in the association of skin disease and liver disease in both pellagra and kwashiorkor. 
The data for losses of nutrients in sweat and from the skin surface have almost all been obtained from experiments on fit and well-nourished Europeans; the values may well be very different if the metabolism of the skin is altered by malnutrition and the prolonged climatic effects of tropical exposure. In general, in malnutrition we should expect the losses to be smaller, but as the co.... -ration mechanisms of the skin may be damaged the losses of some nutrients might well be increased.

We should also consider whether the skin is able to fulfil its thermo-regulatory functions adequately in the presence of malnutrition and disease and if this function does become abnormal, how much it, in turn, may further impair the nutritional status. For the present there would seem to be no adequate answers to these questions. The results of recent work on the physiological responses to hot environments of young men at the National Hospital, Queen Square, London, and also at the Royal Naval Tropical Research Unit, Singapore, would provide a most useful starting point for such an investigation (Medical Research Council, I958).

In case this review might have seemed to overstress the importance of heat stress in tropical nutrition, it is perhaps as well to conclude by pointing out that many of the so-called tropical diseases are not primarily caused by any particular environment but, like kwashiorkor, are the result of the close association of poverty and ignorance with the tropical areas of the world (Waterlow, 1955). Even so, since the effect of the heat stress of tropical life may play some part, albeit a small one, we should know more about its role than we do at present.

\section{REFERENCES}

Adam, J. M. \& Ferres, H. M. (1954). F. Physiol. 125, 2 I $P$.

Aegineta, Paulus. (1884). The Seven Books of Paulus Aegineta translated by Francis Adams, Vol. I. London: Printed for the Sydenham Society by C. \& J. Adlard.

Conn, J. W. (1949). Advanc, intern. Med. 3, 373.

Dawbarn, M. (1938). Aust. F. exp. Biol. med. Sci. 16, г59.

Dill, D. B., Hall, F. G. \& Edwards, H. T. (1938). Amer. F. Physiol. 123, 412.

Ferres, H. M., Fox, R. H. \& Lind, A. R. (1954). Rep. Royal Navy Personnel Research Committee, med. Res. Coun., Lond., no. R.N.P. 54/818.

Food \& Agricultural Organization of the United Nations: Committec on Calorie Requirements (I957). F.A.O. nutr. Stud. no. 15 .

Fuhrman, F. A. (1956). The Physiology of Induced Hypothermia. Publ. Nat. Res. Coun., Wash., no. 45I, Part I, p. 5I. [R. D. Dripps, editor.]

Gillman, J. \& Gillman, T. (I95 I). Perspectives in Human Malnutrition. New York: Grune \& Stratton.

Gray, E. le B., Consolazio, F. C. \& Kark, R. M. (I95I). F. appl. Physiol. 4, 270.

Hancock, W., Whitehouse, A. G. R. \& Haldane, J. S. (1929). Proc. roy. Soc. B, ro5, 43.

Hansen, J. D. L. (1956). S. Afr. F. Lab. clin. Med. 2, 206.

Himsworth, H. P. (1950). Lectures on the Liver and its Diseases, and ed. Oxford: Blackwell Publications. Johnson, R. E. \& Kark, R. M. (1947). Science, 105, 378.

Klauder, J. V. \& Brown, H. (1936). Arch. Derm. Syph. 34, 568.

Ladell, W. S. S. (1951). F. Physiol. r12, I 5 P.

Lobitz, W. C. \& Osterberg, A. E. (1947). Arch. Derm. Syph. 56, 8 I 9.

Macpherson, R. K. (1956). Environmental Problems in Tropical Australia. Report of a Survey of Living Conditions in Tropical Australia with Special Reference to the Northern Territory and New Guinea. Canberra: Commonwealth Government Printer.

McCance, R. A. \& Barrett, A. M. (195I). In Spec. Rep. Ser. med. Res. Coun., Lond., no. 275, p. 83. Medical Research Council. (1958). Physiological Responses to Hot Environments. Spec. Rep. Ser. med. Res. Coun., Lond. (To be published). 
Mitchell, H. H. \& Edman, M. (195I). Nutrition and Climatic Stress with Particular Reference to Man. Springfield, Ill.: Charles C. Thomas.

Mitchell, H. H. \& Hamilton, T. S. (1 949). 7. biol. Chem. 178, 345.

Parkes, E. A. (1883). A Manual of Practical Hygiene, 6th ed. London: J. \& A. Churchill.

Pinkus, H. (1952). F. invest. Dermat. 19, 43 I.

Politzer, W. M. \& Wayburne, S. (1957). Brit. F. Nutr. II, I05.

Quenouille, M. H., Boyne, A. W., Fisher, W. B. \& Leitch, I. (1951). Tech. Commun. Bur. Anim. Nutr., Aberd., no. I7.

Rothman, S. (1954). Physiology and Biochemistry of the Skin. Chicago: University of Chicago Press.

Selye, H. (1946). \%. clin. Endocrin. 6, I 17.

Thurman, F. M. \& Ottenstein, B. (1952). F. invest. Dermat. r8, 333.

Waterlow, J. C. (editor). (I955). Protein Malnutrition. New York: Josiah Macy Jr. Foundation.

van Heyningen, R. \& Weiner, J. S. (195I). $\mathcal{~ Y . ~ P h y s i o l . ~ I r 2 , ~ I 3 ~} P$.

Weiner, J. S. \& van Heyningen, R. (1949). Nature, Lond., 164, 35 r.

\section{Some quantitative interrelationships among thermal environment, human metabolism and nutrition}

\section{By R. E. Johnson and F. SARgent, II, Department of Physiology, University of Illinois,} Urbana, Ill., U.S.A.

When a healthy man is exposed to an environmental extreme, to restriction of water, and to caloric deprivation, all at the same time, dramatic changes may occur in the efficiency of the body as a whole, and in the function of individual organs and systems. Important work has been published in this country and abroad on this 'survival problem', especially on two important aspects: environmental protection and the nutritional physiology of men living on survival rations. We shall not attempt to summarize comprehensively the work of others, but will confine this presentation to a few quantitative generalizations on metabolic phenomena, arising largely from our own studies. Details of methods, complete data on clinical, biochemical, physiological and nutritional observations, and practical applications for emergency feeding are to be found in four technical military reports (Sargent, Sargent, Johnson \& Stolpe, 1954, 1955; Sargent, Sargent \& Johnson, 1957; Sargent \& Johnson, 1958).

\section{Methods}

In all, a total of 8698 subject-days is the basis for our conclusions; three major studies were conducted. In 1953, twelve volunteer students lived under temperate conditions and performed moderate daily work. In 1954, roo volunteer airmen simulated survival in the winter cold of Wisconsin. In 1955 , 100 volunteer airmen simulated survival in the moist summer heat of Indiana. Experimental design and measurements were basically the same in all three studies, so that statistically valid comparisons could be made between subjects in any one study, and among regimens in all three studies.

A preperiod of 2 weeks was followed by an experimental period of 2 weeks. There ensued a recovery period of 2 weeks. During the preperiods and recovery periods all subjects lived on the same adequate diet, with unlimited fluids and 